\title{
The effect of probiotics on bowel movement and metabolic parameters in schizophrenia patients: a retrospective chart review
}

\author{
Takahiko NAGAMINE ${ }^{1 *}$ and Masaru NAKAMURA ${ }^{2}$ \\ ${ }^{1}$ Sunlight Brain Research Center, 4-13-18 Jiyugaoka, Hofu, Yamaguchi 747-0066, Japan \\ ${ }^{2}$ Department of Psychiatric Internal Medicine, Kosekai-Kusatsu Hospital, Hiroshima, Japan \\ Received April 7, 2020; Accepted May 3, 2020; Published online in J-STAGE May 16, 2020
}

Key words: constipation, metabolic parameters, probiotics, schizophrenia patients

Schizophrenia patients have a higher prevalence of constipation and metabolic disorders due to the disease itself and antipsychotics which possess anticholinergic and antihistaminergic effects [1]. Probiotics have the benefits of regulating bowel movement and ameliorating metabolic disorders [2]. However, limited inferences can be made regarding the efficacy of probiotics in schizophrenia patients. To investigate the effect of probiotics on bowel movement and metabolic parameters in schizophrenia patients, we conducted a retrospective chart review of schizophrenia inpatients who were treated with a combination probiotic including Streptococcus faecalis $2 \times 10^{8} \mathrm{CFU} /$ day, Bacillus mesentericus $1 \times 10^{7} \mathrm{CFU} /$ day, and Clostridium butyricum $5 \times 10^{7} \mathrm{CFU} /$ day for constipation for more than two months.

We used the Bristol stool form scale [3], and scored stools with the number corresponding to the stool form type, i.e. type 1 (separate hard lumps, like nuts) $=1$, type 2 (sausage-shaped, but lumpy $)=2$, and day without evacuation $=0$. These scores were collected from charts on seven consecutive days at baseline and at one and two months after treatment. To evaluate time-sequential changes in intestinal function, the defecation score was defined and calculated as the sum of the Bristol scale scores minus 4 (normal stool form) during a week. Multiple comparisons of the defecation score and metabolic parameters were performed at baseline and at one and two months using repeated-measures ANOVA. This protocol is registered in the UMIN Clinical Trials Registry (ID: UMIN000033804).

Subjects consisted of 22 men with a mean age of 59.6 years and 25 women with a mean age of 62.5 years. The defecation score markedly improved from $-9.6 \pm 1.0$ at baseline to $-6.5 \pm$ 0.9 after two months ( $p=0.03$; Fig. 1). Metabolic parameters such as FBS, AST and ALT decreased after a month of treatment with probiotics, although not significantly. At one and two months, TG and TG/HDL-C ratio converged at lower levels compared with the baseline values, although the differences were not significant. HDL-C, LDL-C and body weight remained unchanged (Table 1).
Probiotics significantly relieved constipation among schizophrenia inpatients in this study, especially at two months of treatment. It might take time for probiotics to ameliorate dysbiosis. This result is in agreement with the report that probiotics stimulate intestinal peristalsis by modifying intestinal microbiota and the systemic immune response [4]. The combination probiotic used in this study contained three different kinds of useful bacteria. $S$. faecalis and $B$. mesentericus can produce lactic acid and an incidental increase in Bifidobacterium, and consequently dysbiosis may improve. Moreover, a recent experiment indicated that butyrate produced by $C$. butyricum attenuates constipation by promoting intestinal hormones secretion [5]. The sequential change in the TG/HDL-C ratio from 3.44 at baseline to 2.00 at one month and 2.05 at two months might have indicated an improvement in insulin resistance with the probiotics. The TG/ HDL-C ratio is an atherogenic index that has proven to be a highly significant independent predictor of myocardial infarction, even stronger than the TC/HDL-C ratio and LDL-C/HDL-C ratio [6], since it was shown that TG levels increased while HDL-C levels decreased in individuals with insulin resistance [7]. This result is in agreement with the report that probiotics could lead to stimulation of insulin signaling through amelioration of dysbiosis [8].

In recent years, the effect of probiotics on constipation and metabolism has been increasingly investigated, and promising results have been reported [9]. However, the majority of the current evidence is derived from animal studies. This preliminary clinical study showed that a combination probiotic may improve constipation and insulin resistance in schizophrenia patients. A recent study indicated that microbiota of firstepisode, drug-naïve schizophrenia patients were characterized by decreased short-chain fatty acid-producing bacteria, such as those of the Faecalibacterium and Lachnospiraceae genera [10]. Derangements of the gut microbiome have been linked to central nervous system disorders, including schizophrenia [11].

*Corresponding author. Takahiko Nagamine (E-mail: tnagamine@outlook.com) 


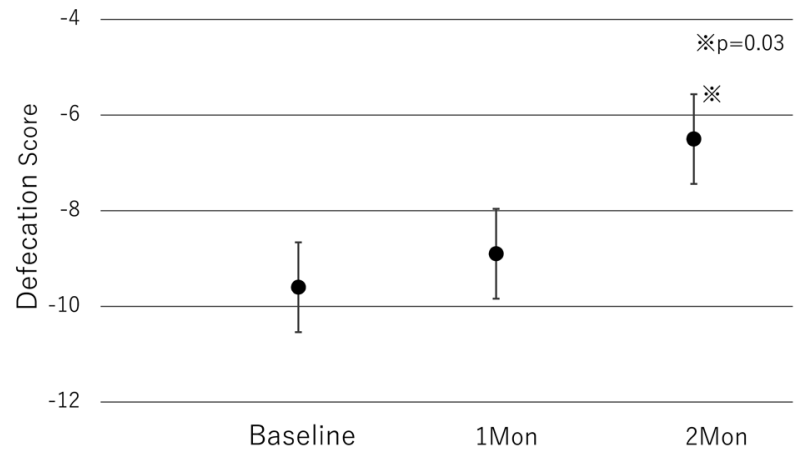

Fig. 1. Sequential changes of defecation scores using the Bristol stool form scale.

Therefore, further clinical studies are warranted to elucidate the utility of probiotics for schizophrenia patients.

\section{CONFLICT OF INTEREST}

The authors have no conflicts of interest relevant to the content of the article.

\section{REFERENCES}

1. Chougule A, Praharaj SK, Bhat SM, Sharma PSVN. 2018. Prevalence and factors associated with clozapine-related constipation: An observational study. J Clin Psychopharmacol 38: 42-46. [Medline] [CrossRef]

2. Cenit MC, Sanz Y, Codoñer-Franch P. 2017. Influence of gut microbiota on neuropsychiatric disorders. World J Gastroenterol 23: 5486-5498. [Medline] [CrossRef]

3. Chumpitazi BP, Self MM, Czyzewski DI, Cejka S, Swank PR, Shulman RJ. 2016 Bristol Stool Form Scale reliability and agreement decreases when determining Rome III stool form designations. Neurogastroenterol Motil 28: 443-448. [Medline] [CrossRef]

4. Kamiya S. 2011. Effect of probiotics on intestinal infections. Intest Res 9: 171-178. [CrossRef]

5. Zhuang M, Shang W, Ma Q, Strappe P, Zhou Z. 2019. Abundance of probiotics and butyrate-production microbiome manages constipation via short-chain fatty acids production and hormones secretion. Mol Nutr Food Res 63: e1801187. [Medline] [CrossRef]

6. Gaziano JM, Hennekens CH, O'Donnell CJ, Breslow JL, Buring JE. 1997. Fasting triglycerides, high-density lipoprotein, and risk of myocardial infarction. Circulation 96: 2520-2525. [Medline] [CrossRef]

7. Quispe R, Martin SS, Jones SR. 2016. Triglycerides to high-density lipoproteincholesterol ratio, glycemic control and cardiovascular risk in obese patients with type 2 diabetes. Curr Opin Endocrinol Diabetes Obes 23: 150-156. [Medline] [CrossRef]

8. Yoo JY, Kim SS. 2016. Probiotics and prebiotics: present status and future perspectives on metabolic disorders. Nutrients 8: 173. [Medline] [CrossRef]

9. Dimidi E, Christodoulides S, Scott SM, Whelan K. 2017. Mechanisms of action of probiotics and the gastrointestinal microbiota on gut motility and constipation. Adv Nutr 8: 484-494. [Medline] [CrossRef]

10. Zhang X, Pan LY, Zhang Z, Zhou YY, Jiang HY, Ruan B. 2020. Analysis of gut mycobiota in first-episode, drug-naïve Chinese patients with schizophrenia: a pilot study. Behav Brain Res 379: 112374. [Medline] [CrossRef]

11. Ng QX, Soh AYS, Venkatanarayanan N, Ho CYX, Lim DY, Yeo WS. 2019. A systematic review of the effect of probiotic supplementation on schizophrenia symptoms. Neuropsychobiology 78: 1-6. [Medline] [CrossRef]
Table 1. Metabolic parameters at baseline and at one and two months after combination probiotic treatment

\begin{tabular}{|c|c|c|c|}
\hline \multicolumn{4}{|l|}{ Outcome Measure } \\
\hline & Time point (month) & & $\mathrm{p}$ \\
\hline \multirow[t]{3}{*}{$\mathrm{BW}(\mathrm{kg})$} & Baseline & $57.1 \pm 2.0$ & $\mathrm{n} / \mathrm{a}$ \\
\hline & 1 & $56.5 \pm 1.9$ & 0.952 \\
\hline & 2 & $57.0 \pm 1.9$ & 0.769 \\
\hline \multirow[t]{3}{*}{$\operatorname{AST}(\mathrm{U} / \mathrm{L})$} & Baseline & $21.6 \pm 1.2$ & $\mathrm{n} / \mathrm{a}$ \\
\hline & 1 & $19.2 \pm 1.2$ & 0.644 \\
\hline & 2 & $18.5 \pm 1.0$ & 0.373 \\
\hline \multirow[t]{3}{*}{$\operatorname{ALT}(\mathrm{U} / \mathrm{L})$} & Baseline & $22.3 \pm 4.3$ & $\mathrm{n} / \mathrm{a}$ \\
\hline & 1 & $18.0 \pm 1.9$ & 0.721 \\
\hline & 2 & $16.5 \pm 1.4$ & 0.362 \\
\hline \multirow[t]{3}{*}{$\mathrm{TG}(\mathrm{mg} / \mathrm{dL})$} & Baseline & $142.4 \pm 41.2$ & $\mathrm{n} / \mathrm{a}$ \\
\hline & 1 & $99.8 \pm 7.8$ & 0.126 \\
\hline & 2 & $101.7 \pm 9.4$ & 0.171 \\
\hline \multirow[t]{3}{*}{ HDL-C (mg/dL) } & Baseline & $56.4 \pm 2.9$ & $\mathrm{n} / \mathrm{a}$ \\
\hline & 1 & $56.7 \pm 3.0$ & 0.89 \\
\hline & 2 & $55.7 \pm 2.6$ & 0.934 \\
\hline \multirow[t]{3}{*}{ LDL-C (mg/dL) } & Baseline & $111.4 \pm 4.9$ & $\mathrm{n} / \mathrm{a}$ \\
\hline & 1 & $105.9 \pm 5.1$ & 0.801 \\
\hline & 2 & $108.3 \pm 5.5$ & 0.949 \\
\hline \multirow[t]{3}{*}{ TG/HDL-C } & Baseline & $3.44 \pm 1.44$ & $\mathrm{n} / \mathrm{a}$ \\
\hline & 1 & $2.00 \pm 0.20$ & 0.161 \\
\hline & 2 & $2.05 \pm 0.22$ & 0.206 \\
\hline \multirow[t]{3}{*}{$\mathrm{FBS}(\mathrm{mg} / \mathrm{dL})$} & Baseline & $94.5 \pm 3.8$ & $\mathrm{n} / \mathrm{a}$ \\
\hline & 1 & $87.0 \pm 2.1$ & 0.069 \\
\hline & 2 & $89.0 \pm 2.7$ & 0.131 \\
\hline
\end{tabular}

Values are mean \pm SE unless otherwise specified.

$p$ values, for intragroup comparisons for each time point relative to the baseline values

$\mathrm{p}$ values are considered statistically significant at $<0.05$.

n/a: not applicable; BW: body weight; AST: aspartate aminotransferase; ALT: alanine amiotransaminase; TG: triglyceride; LDL-C: low-density lipoprotein cholesterol; HDL-C: high-density lipoprotein cholesterol; TG/HDL: ratio of TG to HDL-C; FBS: fasting blood glucose. 